\title{
Bio-psychosocial determinants of cardiovascular disease in a rural population on Crete, Greece: formulating a hypothesis and designing the SPILI-III study
}

Christos Lionis $^{1 *}$, Dimitrios Anyfantakis ${ }^{1}$, Emmanouil K Symvoulakis ${ }^{1}$, Sue Shea ${ }^{1,2}$, Demosthenes Panagiotakos ${ }^{3}$, Elias Castanas ${ }^{4}$

\begin{abstract}
Background: In 1988, the SPILI project was established in order to evaluate the cardiovascular disease (CVD) risk profile of the inhabitants of Spili, in rural Crete, Greece. The first reports from this project revealed that against the unfavourable risk factors' profile observed, only a few men with a previous myocardial infarction were encountered. A follow-up study (SPILI II) was performed twelve years after the initial examination, and the unfavourable cardiovascular risk profile was re-confirmed.

Presentation of the Hypothesis: This paper presents a hypothesis formulated on the basis of previous research to investigate if dynamic psycho-social determinants, including social coherence of the local community, religiosity and spirituality, are protective against the development of coronary heart disease in a well-defined population.

Testing the Hypothesis: A follow-up examination of this Cretan cohort is currently being performed to assess the link between psychosocial factors and CVD. Psychosocial factors including sense of control, religiosity and spirituality are assessed in together with conventional CVD risk factors. Smoking and alcohol consumption, as well as dietary habits and activity levels are recorded. Oxidative stress and inflammatory markers, as well as ultrasound measurement of carotid intima media thickness, a preclinical marker of atherosclerosis, will also be measured.

Implications of the hypothesis tested: The issue of the cardio-protective effect of psycho-social factors would be revisited based on the results of this Cretan cohort; nevertheless, further research is needed across different subpopulations in order to establish a definite relationship. A comprehensive approach based on the aspects of biosocial life may result in more accurate CVD risk management.
\end{abstract}

\section{Background}

Cardiovascular disease (CVD) represents the leading cause of mortality in both the industrialised and developing world [1]. Major risk factors on the pathogenesis and precipitation of CVD include age, gender, hypertension, dyslipidaemia, smoking and diabetes [2]. However, particular emphasis has also been given to the role of psycho-social determinants, such as social isolation, chronic life stress, anxiety, hostility and depression [3].

\footnotetext{
* Correspondence: lionis@galinos.med.uoc.gr

'Clinic of Social and Family Medicine, Faculty of Medicine, University of Crete, Greece

Full list of author information is available at the end of the article
}

It has been reported that the etiologic link between psycho-social determinants and atherosclerosis may be through the maintenance of aggravating lifestyle behaviours and the discouragement of their modification, or due to direct endothelium damaging [3]. Evidence suggests that low socio-economic status, social isolation, lack of social support, familial and occupational stress, negative emotions including depression and hostility, may aggravate the prognosis and clinical course in patients with coronary heart disease (CHD) [4]. Data retrieved from human and animal studies link sympathetic nervous system hyperactivity, triggered by psychological stimuli, with accelerated development of carotid
C Biomed Central

C 2010 Lionis et al; licensee BioMed Central Ltd. This is an Open Access article distributed under the terms of the Creative Commons Attribution License (http://creativecommons.org/licenses/by/2.0), which permits unrestricted use, distribution, and reproduction in any medium, provided the original work is properly cited. 
atherosclerosis [3]. It has been reported that chronic stress conditions and negative emotional states promote atherosclerosis through an increased output from the sympathetic nervous system and hypothalamic-pituitaradrenal axis, leading to a variety of adverse peripheral effects, including inflammation [5]. It is also remarkable that psycho-social variables tend to synergistically interplay with conventional risk factors, enhancing the risk for cardiac events [3].

In 1988, a research project was launched, aiming to explore the cardiovascular risk profile of the inhabitants of Spili in rural Crete, Greece [6]. The study (SPILI I) was performed in a primary health care centre located in the Cretan village of Spili, and comprised of permanent residents $(\mathrm{n}=445)$ aged $15-79$ years. The overall attendance rate was $77 \%(n=343)$. Despite an unfavourable profile in terms of smoking prevalence, hypertension, diabetes and increased alcohol intake, the study's investigators found only $1 \%$ (3) of the examined subjects with a previous myocardial infarction [6]. The investigators suggested a possible cardio-protective role related to the closely-knit social relationships, the low unemployment rate, and the potential benefit of certain dietary habits, such as the high consumption of olive oil [6].

A follow-up study was performed twelve years after the initial examination (i.e., in 2000), with the aim of describing the trends of CHD risk factors over time and discussing some key points on the natural course of the disease (SPILI II) [7]. The target population consisted of all inhabitants of Spili who were originally examined in 1988 , and who were still living in the area [ $\mathrm{n}=248]$. A total number of 200 people were re-examined (overall participation rate $80.7 \%$ ). Hypertension prevalence had increased in almost every age group, while obesity represented a more important problem compared to 1988 , most likely as a result of sedentary life style [7]. Furthermore, an unfavourable trend was observed for diabetes, particularly in women. Moreover, an increase in the number of middle-aged women (i.e., 45-64 years) who currently smoked was recorded. It is reported that Greece has the highest percentage of adult tobacco use worldwide [8]. Despite these findings, signs of clinically evident CHD were still scarce representing a challenging motivation for further research [7].

This article illustrates potential links between dynamic psycho-social determinants (social coherence of the local community, religiosity and spirituality) and coronary heart disease in a well-defined population sub-group on Crete with the aim to formulate a new Cretan hypothesis and discuss the design of a further ongoing follow-up study.

\section{Presentation of the hypothesis}

Certain studies have attempted an explanation for the low CHD incidence on Crete, with a main focus on the
Mediterranean diet [9]. Furthermore, specific life-style characteristics, such as adherence to the Greek orthodox religious fast, have been reported to exert a beneficial effect on lipidemic profile and prevalence of obesity [10]. Although interest in the link between psychosocial factors and CHD has increased in the literature in recent years, this subject still seems to be neglected in Greece [11]. Furthermore, the link between a positive psychosocial profile and CHD has not received the expected attention. Despite the high prevalence of smoking, alcohol intake, and a relatively high prevalence of hypertension, diabetes, obesity and hypercholesterolemia, the prevalence of CHD seems to be low in the rural population that we studied. This again raises questions concerning invisible factors contributing to the prevention of CHD. The presence of positive dynamic cardio-protective factors that counterbalance the influence of the previously reported CHD risk factors could offer a potential explanation. Common cultural and traditional aspects of the Cretan cohort, such as family and social support in the context of local communities and daily life management, may serve as a protective role against the manifestations of CHD.

In another study which was implemented in a remote area of Crete a plausible association between religiosity, spirituality and sense of coherence was discussed [12], offering additional thoughts in terms of the link between positive psychosocial factors and CHD in the SPILI project findings. We assume some patho-physiological mechanisms that explain the decreased cardiovascular risk in our studied population through a decreased chronic inflammation. In their review concerning psychosocial factors in the development of coronary artery disease, Strike and Streptoe discussed certain mechanisms through which social and psychological factors impact on coronary atherogenesis, and inflammation was among these [11]. In a UK study by Surtees P et al., a strong sense of coherence was associated with a $30 \%$ reduction in all-cause mortality among 20,500 participants, suggesting its possible protective role against the risk of chronic disease [13]. Further work supports that individuals with a greater sense of coherence present higher levels of self-esteem, optimism and control over their lives, making more likely a response to a stressor with adaptive mechanisms [14].

Therefore, we may hypothesize the existence of biopsycho-social protective factors towards cardiovascular mortality and morbidity, among a Cretan population who is highly homogeneous in terms of ethnic and religious identity. Such factors could include, among others, religiosity and spirituality. The concurrent examination of psycho-social determinants in conjunction with biological markers in longitudinal studies is relatively rare [15]. Individuals who feel hopeless, unable to cope with 
stress or are socially isolated [3] are at considerable risk of developing CVD. More specifically, social determinants may be related to family status, friendships, social and religious group membership [16]. Thus, of particular importance to our project is the observation of a positive correlation between optimism and CVD focusing on sense of control. Given that the church is an important organization for socialization, and that religious beliefs and spirituality can have an impact on feelings of hopelessness or ability to cope with stress, leading to better outcomes [16], the above-cited elements carry great significance for the proposed study. It is also suggested that individuals with high levels of religiosity in terms of church attendance, religious activities and beliefs have better coping abilities, less depression and anxiety and decreased morbidity and mortality compared with those who are less religious [17]. Among explanatory mechanisms through which religious involvement leads to positive health outcomes seems to be the promotion of positive self perceptions and health beliefs, the regulation of individual lifestyles and health behaviours, and the provision of social ties and specific cognitive or behavioral response to stress [17]. Idler et al. suggest that people who are highly involved in worship activities have a greater sense of belonging to their faith group and more positive emotions, offering some novel pathways to be explored in order to better understand the linkage between health outcomes and religion [18].

With regard to the role of socio-economic status (SES) clinical practice guidelines of the European Society of Cardiology on cardiovascular disease prevention consider low SES as an aggravating parameter in the clinical course and prognosis of CHD [19]. Furthermore, it has been reported that other psychosocial risk factors such as depression, hostility, work and family stress tend to cluster among individuals and groups of low SES [19]. In alignment with this, a cross-sectional study among elderly people living on the Eastern Mediterranean islands found that subjects of higher SES were more close to the traditional Mediterranean diet as compared with those in the lowest SES [20]. Researchers suggested that factors such as educational status and income may exert a possible influence on the dietary habits of this population [20].

It is noticed that research regarding bio-psycho-social interactions and health has received limited attention in Greece. However, questionnaires and scales relevant to self-efficacy, sense of coherence [21] and spirituality [22] have been adapted and validated in Greek and are available for the measurement of unseen determinants $[23,24]$. Drawing on the above, we propose an interdisciplinary research effort, which will investigate the interaction between specific psycho-social determinants, religion and biological processes.

\section{Testing the hypothesis}

In order to confirm or refute the "Cretan hypothesis" outlined above, we will conduct a cohort study (SPILI III), which will evaluate the effect of cultural, religious and related psychosocial characteristics (shared within this rural population of Crete), with the relationship between traditional risk factors and CVD (Figure 1). Additionally, where possible, ex inhabitants of Spili who have moved to a more urban and stressful environment will also be recruited, to explore whether these individuals demonstrate a CVD pattern more comparable to global patterns. A control group with patients visiting an urban primary care centre in Crete will also be selected and will be matched with the Spili population group in terms of age and sex.

\section{Measures}

\section{Medical assessment}

A complete medical history will be obtained from participants initially registered in the SPILI I study. Participants will undergo a blood pressure assessment, electrocardiogram and anthropometric measurements (height, weight, hip and waist circumference). Participants will be further evaluated for the presence of markers of atherosclerosis [i.e., fasting serum total cholesterol, low-density lipoprotein (LDL), high-density lipoprotein (HDL) triglicerides], markers of diabetes (i.e., fasting glucose), markers of inflammation [i.e., high sensitivity C-reactive protein (CRP), interleucin-6 (IL-6), fibrinogen] [25,26], as well as oxidative stress [27] and total antioxidant capacity [28]. Ultrasound measurement of carotid intima media thickness, a preclinical marker of atherosclerosis will also be performed $[26,29]$. The 10 -year risk of fatal CVD will be calculated for all participants using the Hellenic SCORE Risk charts [4].

\section{Behavioral assessment}

Dietary patterns (MedDietScore) [30], activity levels (International Physical Activity Questionnaire) [31], smoking, and alcohol habits will also be recorded.

\section{Psychosocial factors' assessment}

Specific attention will be given to the social coherence of the local community [32] and their spiritual and religious beliefs and practices. Validated questionnaires will be used to evaluate sense of coherence (13 item Sense of Coherence Questionnaire) [21,33,34] religious and spiritual beliefs and practices (Royal Free Interview for Spiritual and Religious Beliefs) [22] and depression levels (Beck Depression Inventory-I) [35]. Socioeconomic background and poverty will be estimated after classification on the basis of the mean annual family income and years of education [20]. 


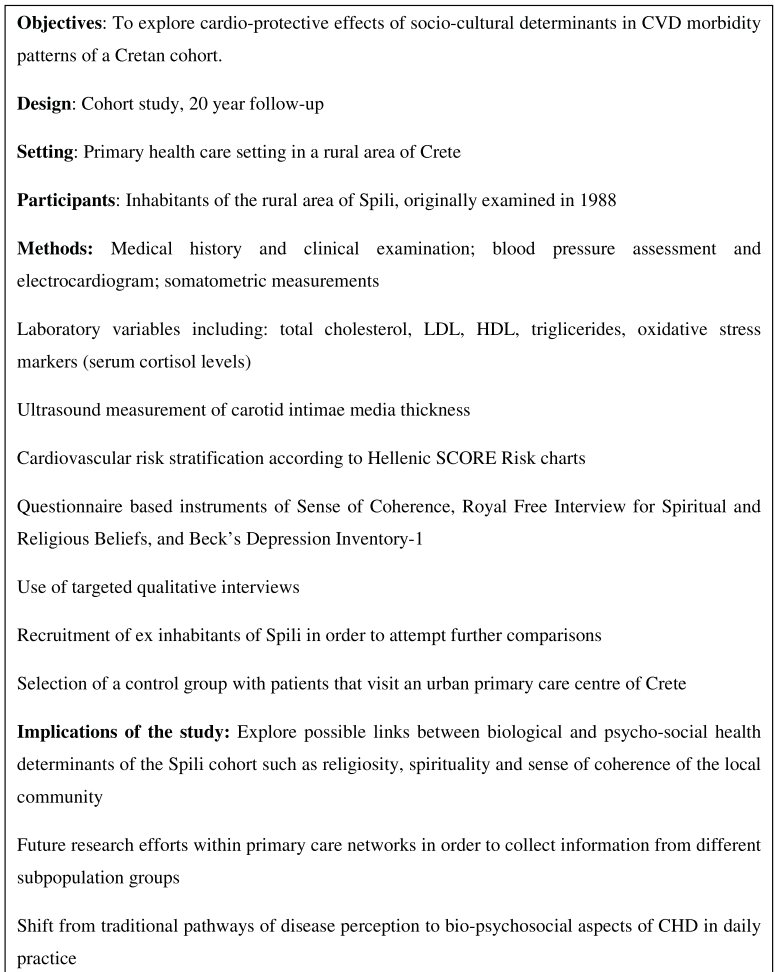

Figure 1 Brief summary of the SPILI-III research protocol study.

A further dimension will be added to the study by the performance of interviews with a sample of the cohort, which could provide additional insight into the qualitative findings. This could represent an opportunity to capture informants' understandings and explanations of their personal experiences of religiosity, spirituality and social coherence accessed within the context of a group defined by geography and common culture.

\section{Statistical analysis}

Incidence rates of CHD and related risk factors will be calculated as the ratio of new cases developed during the preceding years to the number of person-years. Continuous variables will be presented as mean values \pm standard deviation and categorical variables will be presented as frequencies. Associations between categorical variables will be tested using the chi-squared test. Comparisons of mean values of normally distributed variables between those who developed a CVD event and the rest of the participants will be performed using Student's t-test. For the continuous variables that were not normally distributed, the Mann-Whitney non-parametric test will be applied to evaluate the differences in the distributions of the skewed variables between those who developed a CVD event and the remaining participants. Cox PH models with first order interactions will be estimated to test the potential mediating effect of bio-social aspects on the effect of the traditional CVD risk factors on CVD incidence. Sample size calculation revealed that to assess a $\log \{$ hazard ratio\} equal to 0.08 (or hazard ratio $=1.20$ ) with a standard deviation of 1.5 , a sample of 550 cases is needed in order achieve $80 \%$ power at a 0.05 significance level (two sided hypotheses) [36].

\section{Ethical approval and confidentiality}

Approval for this study was obtained by the Institutional Ethics Committee of the University Hospital of Crete (No Protocol:9989/02.09.2008). Written informed consent will be obtained from all participants. The anonymity of the patients' data will be carefully approached. The collected data will be stored at the Clinic of Social and Family Medicine, School of Medicine, University of Crete in which will be accountable from any public access.

\section{Implications of the hypothesis}

The current proposed study aims to explore the extent to which Cretan individuals with greater sense of coherence and high religiosity and spirituality levels, are less likely to be affected by chronic inflammation and atherosclerosis related burden and abnormal levels of the relative bio-markers examined.

The findings will help researchers further explore possible links between biological and psychosocial health determinants. The study could also provide further evidence on the association of other factors such as the Mediterranean diet, which may explain a part of the CVD variation in the population studied. To achieve this, carefully designed research efforts are required in order to explore hypothetical patho-physiological pathways (direct and indirect) through which dynamic psycho-social determinants exert a protective biological effect and counterbalance a negative bio-profile. Furthermore, future interventions and health promotion programmes which take into consideration not only classical cardiovascular morbidity determinants (e.g. smoking, hyperlipidaemia and hypertension) but also adverse psycho-social risk factors may influence our understanding of CVD features in relation to its presentation and natural history. The proposed study may provide an explanation of the so-called "Cretan paradox", by interpreting a range of factors, which may have contributed to the low CVD incidence on the island of Crete during the last decades [37].

\section{Recognized limitations}

A weakness of the proposed study is the inevitably small population size and time related losses with regard to follow-up, since this group has already been monitored for almost two decades. Furthermore, we cannot easily reject or adopt scenarios such as the presence of other confounding factors due to genetic patterns within the 
study population and the beneficial effects of Christian Orthodox fasting on serum lipids and obesity. As Strike and Streptoe underline, it is often difficult to isolate the effects of independent psychosocial variables because they interact and tend to cluster together [11].

\section{Concluding remarks}

In this collaborative proposal, researchers intend to return to the Spili cohort and link biological, psychosocial and socio-cultural data into an overarching model that may provide a clearer understanding of how biological and psycho-social determinants of health intersect and impact on morbidity. The Spili cohort presents a rare opportunity to build on an already solid body of research by way of asking broader questions regarding the relevance of traditional practices and cultural heritage on morbidity and mortality at the individual and community level. We anticipate that certain patterns will be identified which could have both immediate applicability for current clinical and public health concerns, and which may also generate a new round of research questions with regard to the significance of the community for the health and well-being of the individual.

\section{Acknowledgements}

We would like to thank Prof. Nora Ellen Groce and Prof. Lowell Levin from the University of Yale (USA) for their useful comments and advices that they kindly provided on the final draft of this manuscript. The project is partially supported by a grant received from the SANOFI AVENTIS, HELLAS.

\section{Author details}

${ }^{1}$ Clinic of Social and Family Medicine, Faculty of Medicine, University of Crete, Greece. ${ }^{2}$ School of Health and Social Care, University of Greenwich, UK. ${ }^{3}$ Department of Nutrition-Dietetics, Harokopio University, Athens, Greece. ${ }^{4}$ Laboratory of Experimental Endocrinology, School of Medicine, University of Crete, Heraklion, Greece.

\section{Authors' contributions}

$\mathrm{CL}$ conceived and shaped the idea. DA, EKS and $C L$ prepared the first draft of the manuscript. DP provided intellectual input and information on future statistical analysis. SS corrected the manuscript and provided useful suggestions on content, together with editorial support. EC provided scientific and technical input. All authors read and approved the final manuscript.

\section{Competing interests}

The authors declare that they have no competing interests.

Received: 3 May 2010 Accepted: 11 October 2010

Published: 11 October 2010

\section{References}

1. Cardiovascular diseases. [http://www.who.int/mediacentre/factsheets/ fs317/en/index.html ], Last accessed 15.09.2009.

2. Wang TJ: New cardiovascular risk factors exist, but are they clinically useful? Eur Heart J 2008, 29:441-444.

3. Rozanski A, Blumenthal JA, Kaplan J: Impact of psychological factors on the pathogenesis of cardiovascular disease and implications for therapy. Circulation 1999, 99:2192-2217.

4. Panagiotakos DB, Fitzgerald AP, Pitsavos C, Pipilis A, Graham I, Stefanadis C: Statistical modelling of 10-year fatal cardiovascular disease risk in
Greece: the HellenicSCORE (a calibration of the ESC SCORE project). Hellenic J Cardiol 2007, 48:55-63.

5. Rozanski A, Blumenthal JA, Davidson KW, Saab PG, Kubzanski L: The epidemiology, pathophysiology, and management of psychosocial risk factors in cardiac practice: The emerging field of behavioral cardiology. $J$ Am Coll Cardiol 2005, 45:637-651.

6. Lindholm LH, Koutis $A D$, Lionis $C D$, Vlachonikolis $I G$, Isacsson $A$, Fioretos $M$ : Risk factors for ischaemic heart disease in a Greek population. A crosssectional study of men and women living in the village of Spili in Crete. Eur Heart J 1992, 13:291-298.

7. Karalis IK, Alegakis AK, Kafatos AG, Koutis AD, Vardas PE, Lionis CD: Risk factor for ischaemic heart disease in a Cretan rural population: a twelve year follow-up study. BMC Public Health 2007, 7:351.

8. WHO European Country Profiles on Tobacco Control 2003. WHO Regional Office for Europe, 2003. EUR/03/5041305. [http://www.euro.who. int/_data/assets/pdf_file/0006/68118/E80607.pdf], Last accessed 10.07.2010.

9. Kafatos A, Diacatou A, Voukiklaris G, Nikolakakis N, Vlachonikolis J, Kounali D, Mamalakis G, Dontas AS: Heart disease risk-factor status and dietary changes in the Cretan population over the past $30 \mathrm{y}$ : the Seven Countries Study. Am J Clin Nutr 1997, 65:1882-1886.

10. Sarri KO, Tzanakis NE, Linardakis MK, Mamalakis GD, Kafatos AG: Effects of Greek orthodox Christian church fasting on serum lipids and obesity. BMC Public Health 2003, 3:16.

11. Strike PC, Streptoe A: Psychosocial factors in the development of coronary artery disease. Prog Cardiovasc Dis 2004, 46:337-347.

12. Papazisi D, Stefanaki I, Alegakis T, Sapountzi-Krepia D, Sea S, Lionis C: Sense of control and religiosity in a rural region of Crete. Presented at the 9th Wonca Rural Health World Conference, Heraklion Crete, Greece 2009.

13. Surtees $P$, Wainwright $N$, Luben $R$, Khaw KT, Day N: Sense of coherence and mortality in men and women in the EPIC-Norfolk United Kingdom prospective cohort study. Am J Epidemiol 2003, 158:1202-1209.

14. Pallant JF, Lae L: Sense of coherence, well being, coping and personality factors: further evaluation of sense of coherence scale. Personal Individ Differ 2002, 33:39-48.

15. Suls J, Rothman A: Evolution of the biopsychosocial model: Prospects and challenges for health psychology. Health Psychology 2004, 23:119-125.

16. Idler EL, Musick MA, Ellison CG, George LK, Krause N, Ory MG, Pargament KI, Powell LH, Underwwood LG, Williams DR: Measuring multiple dimensions of religion and spirituality for health research: conceptual background and findings from the 1998 general social survey. Research on Aging 2003, 25:327-365.

17. Ellison CG, Levin JS: The religion-health connection: evidence, theory, and future directions. Health Educ Behav 1998, 25:700-720.

18. Idler EL, Boulifard DA, Labouvie E, Chen YY, Krause TJ, Contrada RJ: Looking inside the black box of "Attendance at services": New measures for exploring an old dimension in religion and health research. Int J Psychol Relig 2009, 19:1-20.

19. Graham I, Atar D, Borch-Johnsen K, Boysen G, Burell G, Cifkova R, Dallongeville J, De Backer G, Ebrahim S, Gjelsvik B, Herrmann-Lingen C, Hoes A, Humphries S, Knapton M, Perk J, Priori SG, Pyorala K, Reiner Z, Ruilope L, Sans-Menendez S, Op Reimer WS, Weissberg P, Wood D, Yarnell J, Zamorano JL, Walma E, Fitzgerald T, Cooney MT, Dudina A, Vahanian A, Camm J, De Caterina R, Dean V, Dickstein K, Funck-Brentano C, Filippatos G, Hellemans I, Kristensen SD, McGregor K, Sechtem U, Silber S, Tendera M, Widimsky P, Zamorano JL, Altiner A, Bonora E, Durrington PN, Fagard R, Giampaoli S, Hemingway H, Hakansson J, Kjeldsen SE, Larsen L, Mancia G, Manolis AJ, Orth-Gomer K, Pedersen T, Rayner M, Ryden L, Sammut M, Schneiderman N, Stalenhoef AF, Tokgözoglu L, Wiklund O, Zampelas A: European guidelines on cardiovascular disease prevention in clinical practice: full text. Fourth Joint Task Force of the European Society of Cardiology and other societies on cardiovascular disease prevention in clinical practice (constituted by representatives of nine societies and by invited experts). Eur J Cardiovasc Prev Rehabil 2007, 14: S1-113.

20. Katsarou A, Tyrovolas S, Psaltopoulou T, Zeimbekis A, Tsakountakis N, Bountziouka V, Gotsis E, Metallinos G, Polychronopoulos E, Lionis C, Panagiotakos D: Socio-economic status, place of residence and dietary habits among the elderly: the Mediterranean islands study. Public Health Nutr 2010, 31:1-8. 
21. Karalis I, Langius A, Tsirogianni M, Faresjö T, Nettelbladt P, Lionis C: The translation-validation of the sense of coherence scale into Greek and its use in primary health care. Archives of Hellenic Medicine 2004, 21:195-203.

22. Sapountzi-Krepia D, Raftopoulos V, Sgantzos M, Kotrotsiou E, RoupaDarivaki Z, Sotiropoulou K, Ntourou I, Dimitriadou A: Validation and testretest reliability of the Royal Free Interview for Spiritual and Religious Beliefs when adapted to a Greek population. Ann Gen Psychiatry 2005, 4:6.

23. Karademas EC: Self-efficacy, social support and well-being: The mediating role of optimism. Personality and Individual Differences 2006, 40:1281-1290.

24. Karademas EC, Kafetsios K, Siderides G: Optimism, self-efficacy and information processing of threat and well-being related stimuli. Stress and Health 2007, 23:285-294.

25. Luc G, Bard JM, Juhan-Vague I, Ferrieres J, Evans A, Amouyel P, Arveiler D, Fruchart JC, Ducimetiere P: PRIME Study Group: C-reactive protein, interleukin-6, and fibrinogen as predictors of coronary heart disease: the PRIME Study. Arterioscler Thromb Vasc Biol 2003, 23:1255-1261.

26. Velupillai YN, Packard CJ, Batty GD, Bezlyak V, Burns H, Cavanagh J, Deans K, Ford I, McGinty A, Millar K, Sattar N, Shiels P, Tannahill C: Psychological, social and biological determinans of ill health ( $\mathrm{pSoBid):} \mathrm{study} \mathrm{protocol}$ of a population-based study. BMC Public Health 2008, 8:126.

27. Cai H, Harrison DG: Endothelial dysfunction in cardiovascular diseases: the role of oxidant stress. Circ Res 2000, 87:840-844.

28. Kampa M, Tsaousis V, Maliaraki N, Notas G, Castanas E: A new automated method for the determination of the Total Antioxidant Capacity (TAC) of human plasma, based on the crocin bleaching assay. BMC Chemical Pathology 2002, 2:3.

29. Chambless LE, Heiss G, Folsom AR, Rosamond W, Szklo M, Sharrett AR, Clegg LX: Association of coronary heart disease incidence with carotid arterial wall thickness and major risk factors: the Atherosclerosis Risk in Communities (ARIC) Study, 1987-1993. Am J Epidemiol 1997, 146:483-494

30. Panagiotakos DB, Pitsavos C, Arvaniti F, Stefanadis C: Adherence to the Mediterranean food pattern predicts the prevalence of hypertension, hypercholesterolemia, diabetes and obesity, among healthy adults; the accuracy of the MedDietScore. Prev Med 2007, 23:335-340.

31. Craig CL, Marshall AL, Sjöström M, Bauman AE, Booth ML, Ainsworth BE, Pratt $M$, Ekelund $U$, Yngve A, Sallis JF, Oja P: International physical activity questionnaire: 12-country reliability and validity. Med Sci Sports Exerc 2003, 35:1381-95.

32. Antonovsky A: Unraveling the mystery of health: How people manage stress and stay well. San Francisco: Jossey-Bass 1987.

33. Antonovsky A: The structure and properties of the sense of coherence scale. Social Science and Medicine 1993, 36:725-733.

34. Faresjo T, Karalis I, Prinsback E, Kroon K, Lionis C: Sense of coherence in Crete and Sweden: Key findings and messages from a comparative study. Eur J Gen Pract 2009, 10:1-4

35. Beck AT, Ward CH, Mendelson M, Mock J, Erbaugh J: An Inventory for Measuring Depression. Archives of General Psychiatry 1961, 4:53-63.

36. Whitley E, Ball J: Statistics review 4: Sample size calculations. Critical Care 2002, 6:335-341.

37. Keys A: Seven Countries. In A Multivariate Analysis of Death and Coronary Heart Disease. Edited by: Keys A. MA and London, Harvard University Press Cambridge; 1980:1-381.

\section{doi:10.1186/1756-0500-3-258}

Cite this article as: Lionis et al: Bio-psychosocial determinants of cardiovascular disease in a rural population on Crete, Greece: formulating a hypothesis and designing the SPILI-III study. BMC Research Notes 2010 3:258.

\section{Submit your next manuscript to BioMed Central and take full advantage of:}

- Convenient online submission

- Thorough peer review

- No space constraints or color figure charges

- Immediate publication on acceptance

- Inclusion in PubMed, CAS, Scopus and Google Scholar

- Research which is freely available for redistribution

Submit your manuscript at www.biomedcentral.com/submit 